\title{
LA JUVENTUD DE JUAN PANTOJA DE LA CRUZ Y SUS PRIMEROS RETRATOS. RETRATOS Y MINIATURAS DESCONOCIDAS DE SU MADUREZ
}

\author{
POR \\ MARÍA KUSCHE \\ Dra. por la Universidad de Bonn
}

\begin{abstract}
This article tries to complete some aspects of a biography of the author about Juan Pantoja de la Cruz (1964). Departing from some portraits which can now be atributed to Juan Pantoja de la Cruz the mystery of his early years begin to clarify, up to now only his paintings from age 37 onwards had been known. The early portraits, more lively and expresive than the official works from his period as a courtpainter of Philipp III, and some previousley unknown works of these later years, show new qualities of the painter. Two identified miniatures, give an idea of this side of his oeuvre hitherto known only from documents.
\end{abstract}

Cuando comencé mi tesis sobre Pantoja en 1960 1', el profesor Sánchez Cantón me dijo, al entregarme generosamente toda una serie de documentos sobre el artista que había encontrado: «lo más importante sería aclarar sus años jóvenes». Pero -en las circunstancias de entonces- ya me sentí satisfecha de poder reunir todos los cuadros conocidos de Pantoja y no encontré ninguna pista, ni de obras, ni de documentos, que me llevase a los años anteriores a 1590. En 1590 Pantoja era ya un hombre maduro, de 37 años. Trabajaba con regularidad en la corte, aunque no fue hasta 1596 cuando comenzó a figurar oficialmente como pintor de cámara de Felipe III, sucediéndole de esta manera a Alonso Sánchez Coello. Quedó, pues, sin aclarar el enigma de su juventud.

Partiendo de la base estilística de sus obras firmadas, estudiadas entonces, hoy, con mas experiencia que en aquellos años, y también con suerte, he podido reunir toda una serie de cuadros, piezas del puzzle que nos aclaran, por lo menos en parte, la época joven del pintor. Algunas obras hace poco han ido apareciendo en el mercado de arte y estos eslabones, hasta ahora desconocidos de su obra, a su vez me han llevado a reconocer como suyas otros retratos ya existentes desde hace tiempo, bajo otros nombres, en varias colecciones.

\footnotetext{
1 Kusche M., Juan Pantoja de la Cruz, Madrid, 1964.
} 

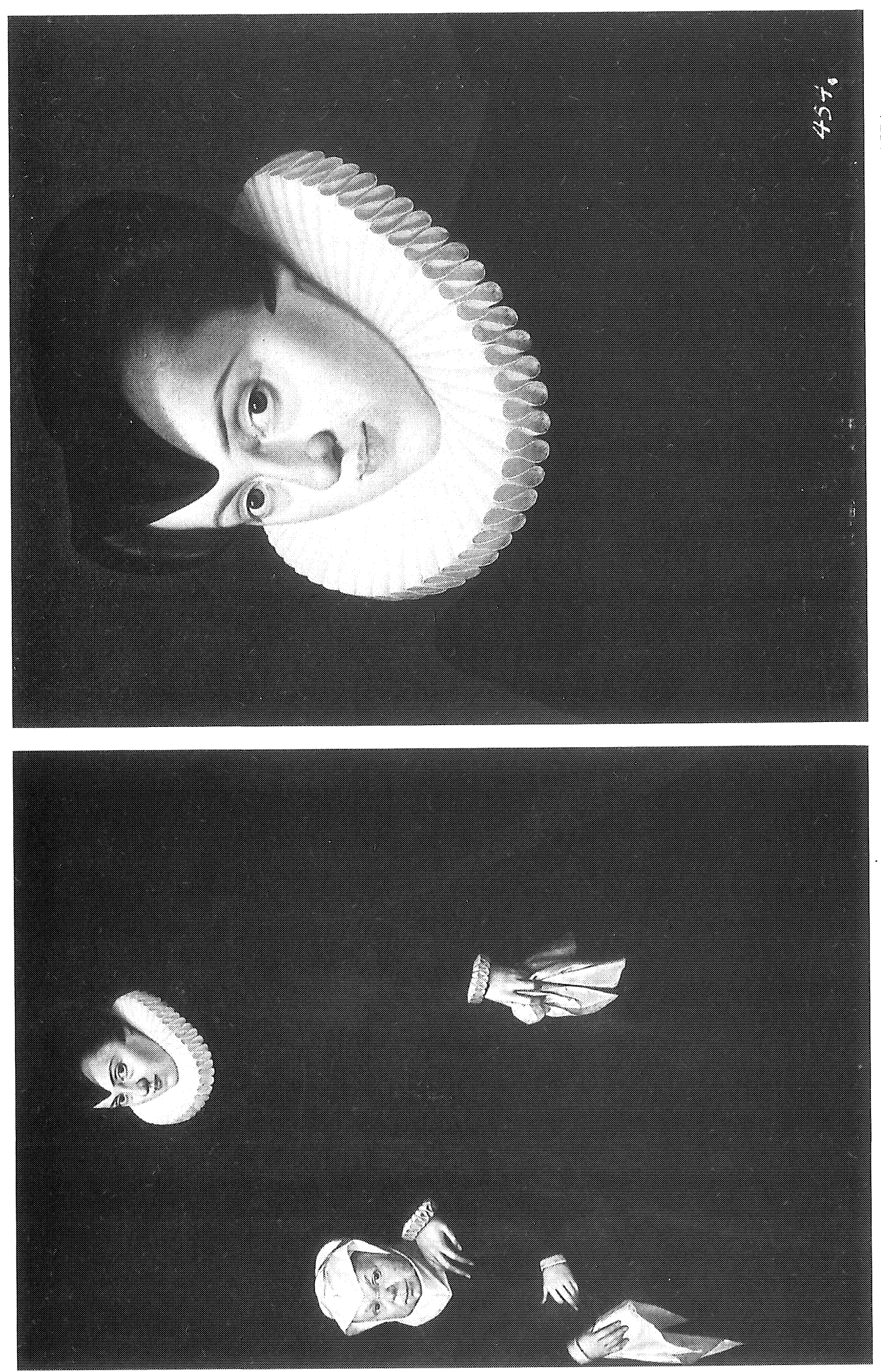

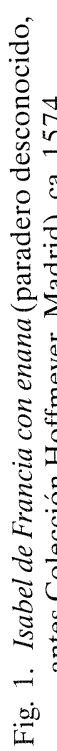




Comienzo como primer eslabón, con una foto antigua de un retrato de cuerpo entero de Isabel de Austria. Reina de Francia, con una enana (fig. 1), perdido en la Guerra Civil, que se encontraba en la antigua colección Hoffmeyer. Isabel, casada con Carlos IX de Francia, fue hermana de Doña Ana -cuarta mujer de Felipe II, ambas hijas de María de Austria y Maximiliano II y sobrinas de Felipe II. Está pintada Isabel en traje de viuda, apoyándose en su enana, tambien de luto, y lleva en letras bien legibles la firma usual del artista "Juan Pantoja de la Cruz».

Isabel nació en 1553, casó en 1570. Cuando Carlos murió en 1574, la viuda volvió a Viena, acompañada de una hija que murió a los pocos años. En 1580, después de la muerte de la Reina Ana, Felipe II quiso casarse con Isabel, pero ella prefirió retirarse al convento de Sta. Dorotea en Viena, fundado por ella, donde murió en 1592.

Poseemos de ella el único retrato firmado de Jorge de la Rúa, que lleva la fecha de 1573. La diferencia de edad entre este retrato y el con la enana debió ser muy poca. La cara de Isabel, aunque más cansada, resignada y estropeada que en el de Rúa, es aún muy joven Se puede suponer que el cuadro fue pintado poco tiempo después de la muerte de su marido, alrededor de 1574/75.

Comparándo este retrato con los posteriores de Pantoja, ante todo con el retrato de 1593, firmado, de María Luisa de Aragón, Duquesa de Villahermosa (Castillo de Nelahozeves, Praga, fig. 3) ${ }^{2}$ y el de la Duquesa de Lerma de ca.1602 (Sevilla, Colección Duque de Medinaceli, fig. $4)^{3}$, toda la concepción y hechura del retrato de Isabel confirma la autoría de Pantoja. La postura en el retrato de la Duquesa de Lerma, con su mano derecha apoyada en un sillón, la otra colgando, con un pañuelo, se ve parecidísima en el de Isabel con enana. Ambas damas llevan trajes negros, alegrados sólo por cinturón el de la duquesa y el de Isabel por un crucifijo en la cintura. Pero la semejanza es más que esto: la representación tan severa y escueta de la figura, la concentración de la luz en cara y manos y, ante todo, la manera de modelar la cara.

Pero si esto aún no fuese suficiente, es la comparación con el busto de Isabel que hoy todavia se encuentra en Innsbruck (Castillo de Ambras (fig. 2)), atribuido a del Monte, la que nos da definitivamente la certeza de que la firma del retrato de Isabel con la enana es auténtica. Este busto es clarísimo de la mano de Pantoja, por la concentración completa en el rostro, por su grandísima plasticidad, por la intensa iluminación de éste.

Se ha atribuido este retrato al neerlandés «del Monte» ${ }^{4}$ y fechado en los años 1580 , por saberse que el pintor en estas fechas había trabajado para Isabel. Pero ni la fecha, ni la atribucion pueden mantenerse en pie. Esta fecha tardía, parece imposible, porque al haber pasado, en este caso, más de siete años desde el retrato de Rúa y habiendo sido, pues, viuda ya más de seis años, su rostro debería haber comenzado a mostrar el peso de los años y no ostentaría la frescura de la juventud que en él se observa, y su luto después de tantos años debía haberse aliviado algo con alguna joya, con algo de encaje en el tocado o por lo menos en el pañuelo. Pero ante todo, se comprende que no puede ser de del Monte comparándolo con sus retratos seguros, que desde 1591 hizo en Graz: el del Archiduque Fernando, posterior Emperador Fernando II, y el de su hermana, la Archiduquesa Gregoria Maximiliana; se ve que estos retratos, inquietos en iluminación, postura y expresión, de tipo muy nórdico, bien poco tienen en común con el busto que se le atribuye.

Tendríamos pues en el retrato de Isabel de Francia la primera prueba de que el silencio que cubre los años jóvenes de Pantoja se debió a su ausencia de España y surge la pregunta, si pintaría este retrato estando Isabel aún en Francia, o estando Isabel ya de vuelta en Viena.

\footnotetext{
2 Kusche, 1964, pp. 81, 156, 157; fig. 23.

3 Kusche, 1964, pp. 75, 151; fig. 16.

4 Heinz G., Schütz K., Porträtgalerie zur Geschichte Österreichs, von 1400-1800 (Catálogo de la Galería de Retratos en el Castillo de Ambras), Viena, 1976, p. 107, fig. 132.
} 
Dos retratos que se encuentran en Buenos Aires, en el Museo Municipal de Arte Español "Enrique Larreta" y que proceden, junto con otros dos, directamente de la antigua Colección Dietrichstein-Nikolsburg en Moravia, dan la respuesta, al mismo tiempo que vuelven a confirmar la autenticidad del retrato de Isabel. Los cuatro cuadros formaban un lote y efectivamente la historia de sus personajes les une: dos son retratos de los Archiduques Rudolfo y Ernesto -réplicas de los retratos para la Galeria del Pardo de Sánchez Coello y sin duda por su calidad de la mano del mismo pintor ${ }^{5}-\mathrm{y}$ dos del preceptor de los dos principes Adán de Dietrichstein (fig. 5) y de su mujer Margarita de Cardona (fig. 6). Llevan el sello inconfundible de la hechura y técnica de Pantoja: el realismo de sus caras tan realzadas que contrasta con la postura jerárquica de sus cuerpos, la técnica suave y fina pero nada suelta.

El de Adán de Dietrichstein, Consejero, Camarero Mayor y Embajador del Emperador Rudolfo, lleva la inscripción: ADAMUS A DIETRICHSTEIN RUDOLPHI II IMPERATORIS SUPRA AULA PRAEFECTUS 1585, el de Margarita de Cardona, en traje de viuda, dice: MARGARITA DE CARDONA ADAMI A DIETRICHSTEIN UXOR y debajo, añadido + MDCIX. El segundo debió pues pintarse después de la muerte de Adán, después de 1590.

Adán, totalmente de negro, al lado de un bufete, y engrandecido por un cortinaje con los típicos pliegues en arista de Pantoja -como los de los retratos de Isabel Clara Eugenia y el Archiduque Alberto en Munich 6 - lleva el toisón con cadena de oro, capa con la cruz de Calatrava, en la mano derecha un bastón de mando, la izquierda apoyada en un sillón.

El retrato de Margarita, aunque en toda su postura y composición -a falta del bufete- coincidiendo con el de Adán, y concebido como pareja de él, debió resultar algo mayor y fue recortado para llegar a la misma medida, perdiéndose en el lado izquierdo parte de la mano y de la silla . Viste Margarita de negro, con lechuguilla y puños de encaje, casi iguales a los del marido. Lleva toca de viuda muy parecida a la de Isabel de Francia, pero blanca, y una beatilla sujeta con un broche, así como un colgante en el pecho y en la mano un pañuelo con rico encaje. En toda la composición del retrato de Margarita se vuelve a observar, como en el de Isabel de Francia, un gran parecido con el de María Luisa de Aragón (fig. 3), con el de la Duquesa de Lerma (fig. 4).

Estos dos retratos del matrimonio Dietrichstein no sólo son un hallazgo en sí, no sólo consolidan la atribución del retrato de Isabel de Francia a Pantoja, sino que el de Margarita tranforma en certeza una sospecha que tengo hace tiempo. El bellísimo retrato de Dama con niña en Praga (Castillo de Nelahozeve) procedente de la antigua Colección Lobkowitz en Raudnitz, que en la exposición de Alonso Sánchez Coello se presentó como retrato de Da. María Manrique de Lara, esposa de Wratislaw de Pernstein y se atribuyó a Jorge de la Rúa ${ }^{7}$, ni representa a este personaje y ni es de este pintor, es una obra de Pantoja de sus años jóvenes.

Comparándolo con el de Margarita viuda vemos que se trata de la misma persona: de Margarita de Cardona joven (fig. 7). No sabemos quién es la niña del retrato. No parece tratarse de una hija, pues las cinco de las que tenemos noticia nacieron entre 1556 y 1560 . Por lo visto terminaron su educación en España y se sabe que casaron con españoles: la mayor con el Conde de Galves y después con Don Juan de Borja, 1580 Ana, dama de las Infantas Isabel y Catalina Micaela, se casa en palacio con Don Antonio de Fonseca, María con Baltasar de la Cerda, Hipólita con Don Alvaro de Córdoba, Beatriz con el Marqués de Mondéjar ${ }^{8}$. Se pudiera tratar pues o de una

5 Kusche, M., La Antigua Galería del Pardo ll: su reconstrucción pictórica, Archivo Español de Arte LXIV (1991), pp. 261-281.

6 Kusche, 1964, p. 147, fig. 9; p. 149, fig. 11.

7 Catálogo de la Exposición Alonso Sánchez Coello y el retrato en la corte de Felipe Il, Museo del Prado, Madrid, juniojulio 1990 , p. 154 , cat. 43 , fig. 43.

8 Aparte de diccionarios genealógicos españoles y alemanes, véase F. J. Bouzá Alvarez, Cartas de Felipe II a sus hijas, Madrid, 1988, nota 109. 


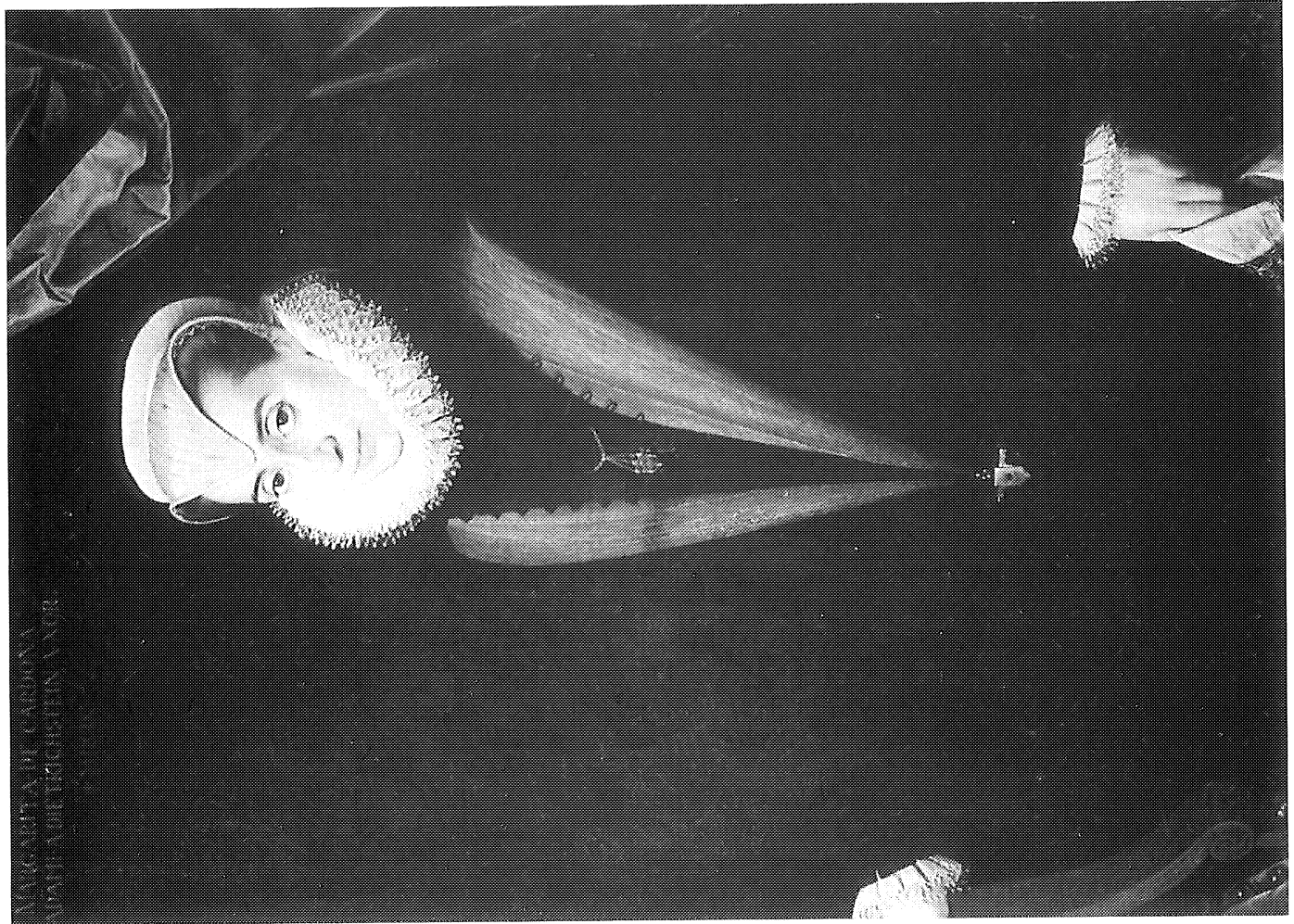

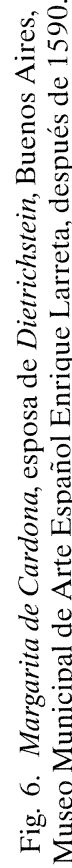

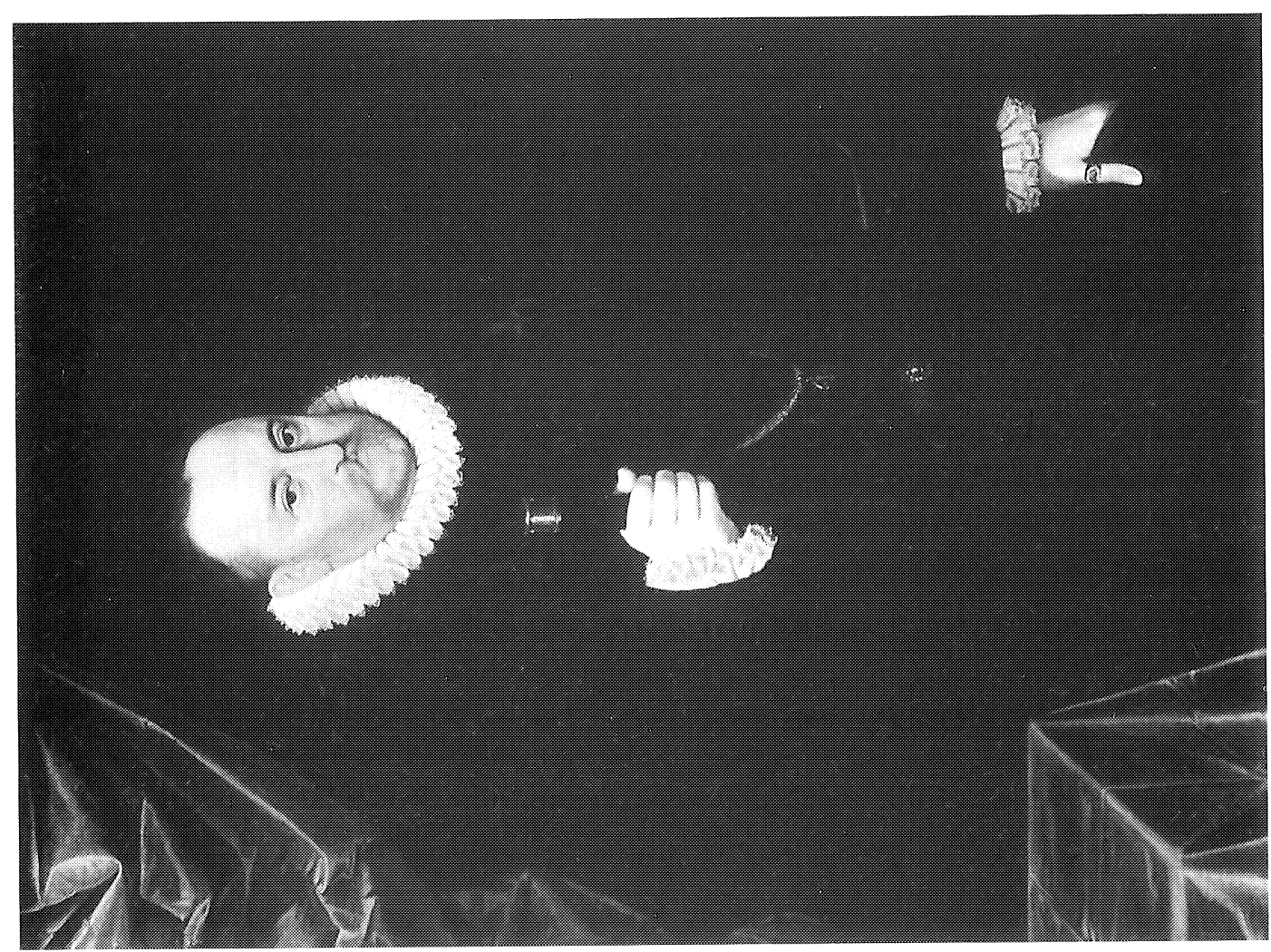

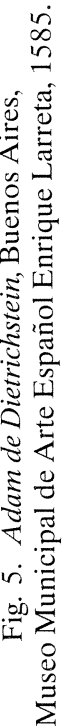




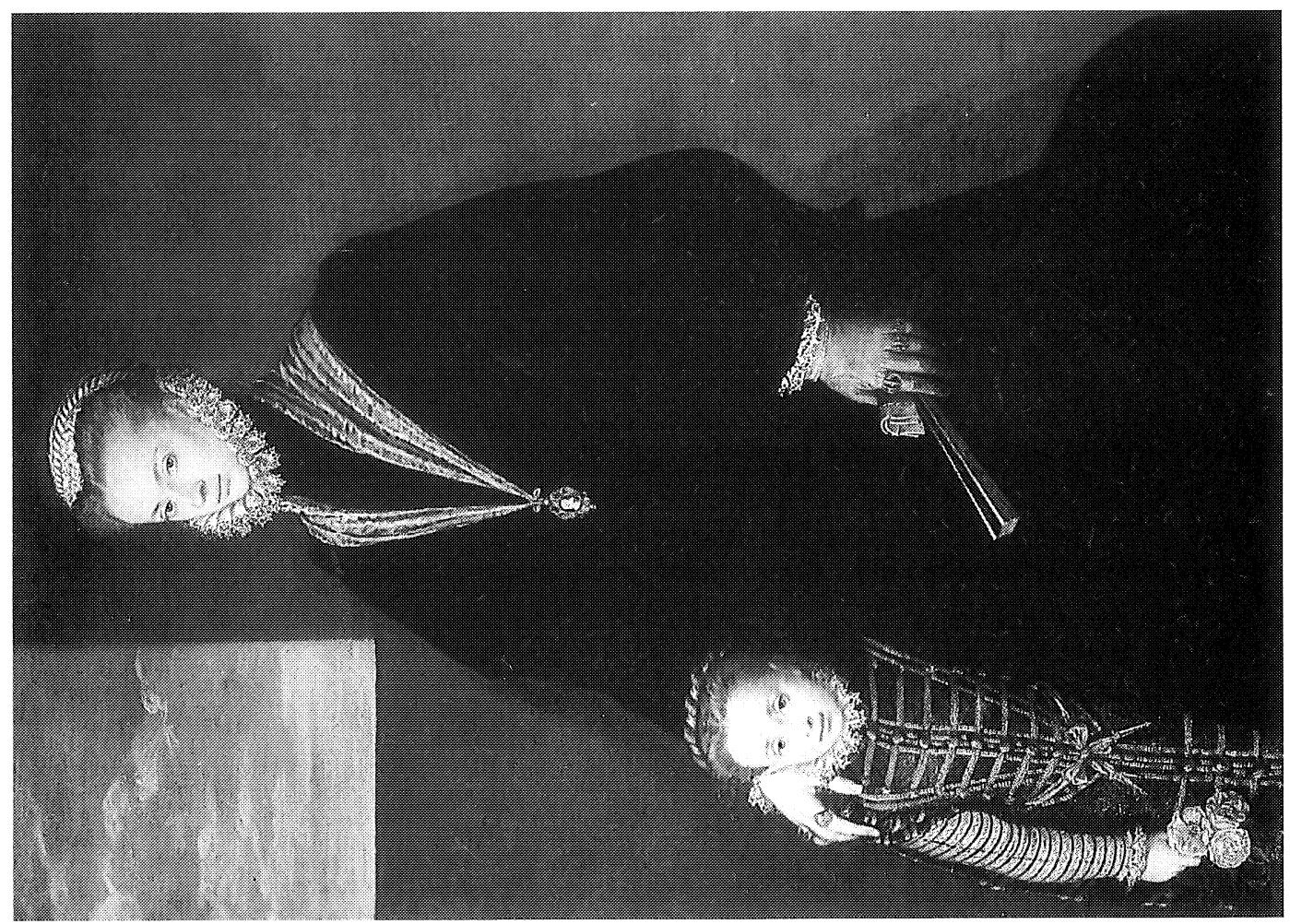

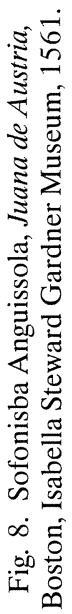

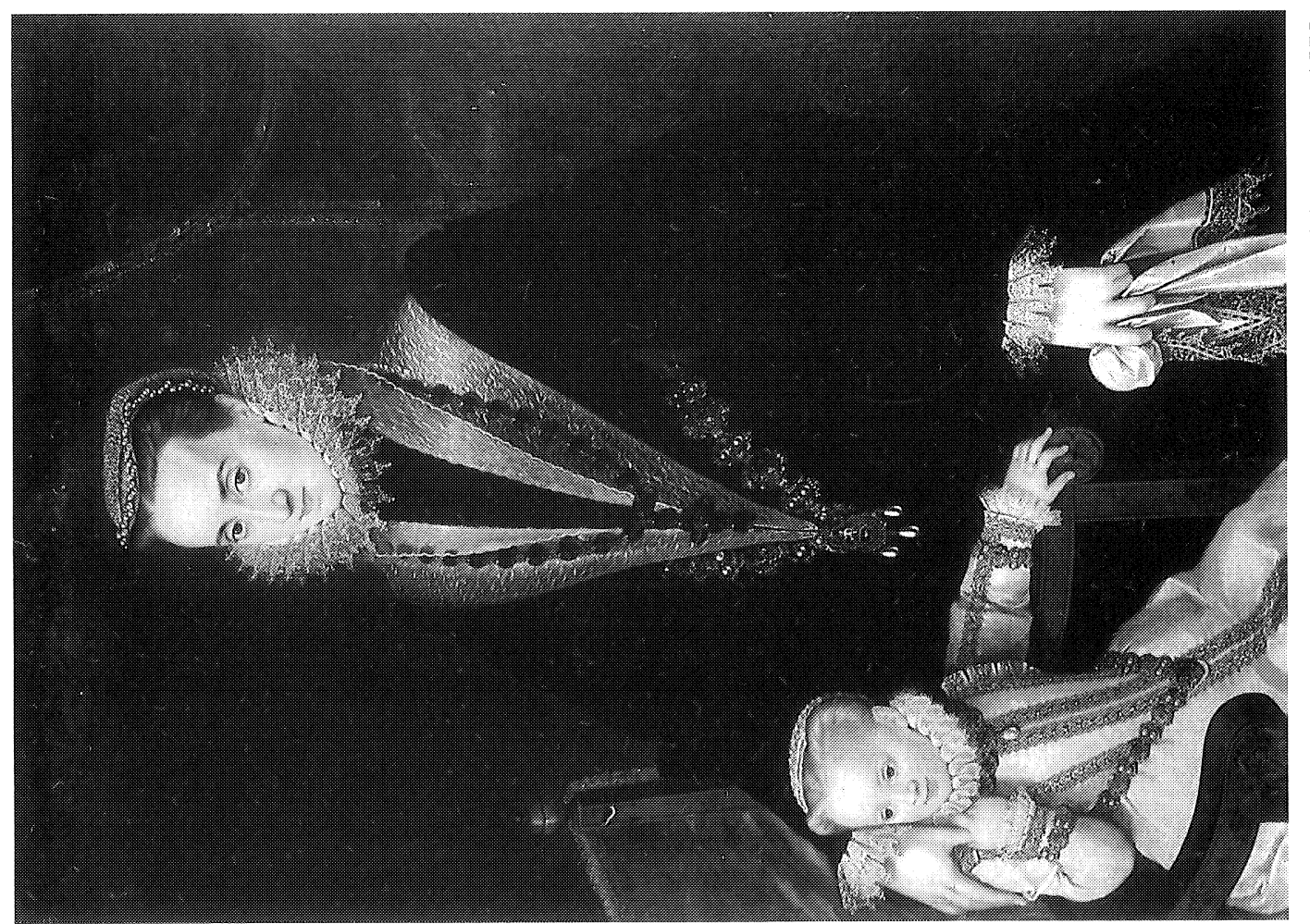


hija nacida ya posteriormente en Bohemia (sólo sabemos que de sus dos hijos el famoso futuro Cardenal nació allí en 1570), o de una de las nietas de Margarita.

Se atribuyó el retrato, en la mencionada exposición, a Jorge de la Rúa por su presunto parecido con el único retrato firmado de este pintor, el de Isabel de Francia (Madrid, Descalzas Reales) 9. Pero ahora se ve claramente, al comparar los cuadros de las damas en el Museo Enrique Larreta y en Nelahozeve, que no sólo se trata del mismo personaje, sino también del mismo pintor. Se puede situar, según el traje, a mediados de los años 70 del siglo xvI, es decir sería más o menos de la misma fecha que el de Isabel de Francia.

Comparándo el retrato de Margarita con niña con el de Isabel de Francia y con el de Margarita de Cardona viuda, se ve que coinciden casi totalmente en la postura de cuerpo y manos, postura que Pantoja repetirá con algunas variaciones a lo largo de su obra. Y comparando el retrato de Margarita con niña con los retratos posteriores de Pantoja se observa la misma forma de realzar la elegancia de una dama a través de la minuciosa y cuidada representación de los detalles de su traje, ayudándose con la concentración de la luz en ellos y los contrastes de color.

La elegante figura de Doña Margarita, en traje de terciopelo negro, con riquísimos encajes blancos en la lechuguilla, los puños, el pañuelo, la cofia, -recamada ésta además en perlas- destaca del fondo oscuro, de la cortina de terciopelo verde. La finísima beatilla que lleva encima un collar de azabache y oro, con colgante en forma de cruz, está prendida al cinturón lujoso de oro, pedrería y perlas. Margarita pasa su brazo derecho por la espalda de la niña que, toda de blanco y oro, se pierde en un sillón grande, tapizado de rojo, cierra su manita alrededor del dedo gordo de la dama para asegurarse de su presencia y desvía la vista hacia algún personaje que le está haciendo gracias para mantenerla quieta, mientras la dama fija la vista en el pintor -en el futuro expectador. La elegante exquisitez de la dama en postura y traje conviene en todo, en postura y presentación, con las damas de Pantoja que conocemos. La niña con su gracia, y los detalles tan realistas de su comportamiento, tiene todo el encanto de los niños de Pantoja. Lo que distingue este cuadro de los conocidos de Pantoja y lo que le une con el de Isabel de Francia y también con un primero de Isabel Clara Eugenia (Pethworth, Sussex, Pethworth House) ${ }^{10}$, es, que aquí el agrado también emana de la dama. Encontramos en este cuadro una faceta de Pantoja que en los retratos de corte oficiales casi se pierde: el deseo de darle una expresión de viva simpatía a sus modelos.

Los Dietrichstein habían vuelto, después de muchos años de residencia en España, en 1571 a Austria y Bohemia. En 1563 Adam de Dietrichstein había ido a España acompañando a los Archiduques Rodolfo y Ernesto a la corte, donde permaneció, como su preceptor y al mismo tiempo embajador de Maximiliano Il, hasta que los Archiduques regresaron a Viena. Desde entonces ocupó altos puestos en la corte de Rodolfo, presenciando primero su coronación como Rey de Hungría en 1572, después de Bohemia en 1575, y Rey de Romanos en el mismo año, y por fin de Emperador del Imperio Romano Germánico en 1576. Siendo Praga la residencia habitual de Rodolfo, también fue la de los Dietrichstein y entrarían inmediatamente en contacto con la nobleza del país. Entre ellos se encontraban los Pernstein. Sin duda Margarita de Cardona, familia de la dama de la Emperatriz María, María Manrique de Lara, esposa de Wratislaw de Pernstein (la abuela de Margarita había sido Francisca Manrique de Lara), buscaría la amistad y el calor de esta familia semiespañola y no es de extrañar que su retrato aún se encuentre en la galería actual de familia Lobkowitz, sucesores de la familia Pernstein, en Nelahozeve.

¿Que podemos deducir de estos cuatro cuadros - de Isabel de Francia con enana, de Margarita de Cardona con niña, de los dos de Adam de Dietrichstein y Margarita de Cardona viudasobre la vida del joven Pantoja?

\footnotetext{
9 Catálogo de la Exposición Alonso Sánchez Coello, op. cit., p. 154, cat. 44, fig. 44.

10 Kusche, 1964, p. 149, fig. 11.
} 
El estilo de los dos primeros llevan el sello de la fuerte influencia de Jorge de la Rúa ${ }^{11}$, pero también en algo la de Sánchez Coello ${ }^{12}$, y la de Sofonisba Anguissola ${ }^{13}$. La delicadeza de los detalles, la amabilidad del conjunto, el esquema de la mano, se asemejan a la forma fina y elegante de Rúa -sin embargo, la fuerza psicológica hacen ver que tambien dejaron rastro las obras de Sánchez Coello, el que Pantoja en su testamento nombra como «mi maestro" ${ }^{14}$. En la manera de combinar una figura adulta con la de una niña hay un reflejo de un cuadro de Sofonisba Anguissola que en el año 1561 había hecho un retrato de Juana de Austria con una niña destinada a novicia (Boston, Isabella Steward Gardener Museum, fig. 8) que en la corte causó impresión ${ }^{15}$.

Recordemos que los primeros dos pintores fueron los que se disputaban entre 1560 y 1568 los encargos de Isabel de Valois, aparte de que trabajaba para la reina, su dama y maestra de pintura, Sofonisba, que con su arte y con su fuerte personalidad les hacía competencia a los dos retratistas y aumentaba de esta forma la competencia entre ellos. Pantoja, nacido alrededor de 1553 , sólo puede haber pasado como aprendiz por sus talleres en los últimos años de Isabel de Valois -en 1568 el futuro pintor tenía aproximadamente quince años.

Cuando en 1568 muere la joven reina, su casa poco a poco se dispersa, las damas españolas vuelven a sus familias, las francesas a Francia, para Sofonisba, por orden del Rey, se comienza a buscar un marido, aunque su salida a Italia aún se retrasa por cuatro años. Jorge de la Rúa, seguramente consciente de que su estilo elegante y mundano tendría menos aceptación en la sencilla corte de la sucesora, Dña. Ana de Austria, que en la alegre de Isabel de Valois, y ante la influencia artística y humana de Sánchez Coello y de Sofonisba Anguissola, decide pasarse a Francia al servicio de la reina Isabel de Austria ${ }^{16}$.

Aunque aún no tenemos una prueba documental que nos asegure una estancia de Pantoja en la corte francesa, ¿qué más probable que el joven, que tampoco podía esperar un porvenir en Madrid, le siguiese a Rúa como su discípulo según todo su estilo parece indicar? Al morir Carlos IX en 1574, Pantoja ya como pintor hecho, con aproximadamente 21 años, en busca de un futuro independiente, seguiría a la Reina Isabel viuda, cuando ésta volvia a Austria con su familia. Allí como pintor español, muy pronto conocería a los Dietrichstein y tambien a los Pernstein ${ }^{17}$, contacto que en años posteriores, de vuelta en Madrid, le llevaría a pintar para los Villahermosa, para los Aragón, emparentados con los Dietrichstein, entrando así en directa competencia con el pintor de la casa, Rolam del Mois ${ }^{18}$.

En 1585, año de la boda de la Infanta Catalina Micaela con el Duque de Saboya, Pantoja, después de pintar el retrato de Adán de Dietrichstein, todavía en Bohemia, volvería a España, seguramente con la esperanza de poder ir reemplazando con el tiempo al anciano Sánchez Coello.

Este regreso queda demostrado por un hermoso retrato de Catalina Micaela (fig. 8, Suiza, Colección Particular) de cuerpo entero, con traje negro de terciopelo adornado con la S de Savoya, enmarcada por ambos lados por un gran cortinaje. La Infanta se apoya en un sillón, forrado de terciopelo rojo y sujeta su pañuelo exactamente de la misma manera que en los retratos anterio-

11 Kusche, M., Sofonisba Anguissola en España, retratista en la Corte de Felipe II junto a Alonso Sánchez Coello y Jorge de la Rúa, Archivo Español de Arte, n. ${ }^{\circ} 248$ (1989), p. 400, nota 48, y Kusche M., Sofonisba e il ritratto di rappresentanza uffiziale nella corte spagnola, en Catálogo de la Exposición «Sofonisba Anguissola e le sue sorelle», Cremona, 1994, p. 131, fig. 17 .

12 Kusche, M., Sánchez Coello Hofmaler Philipps II, en Zeremoniell und Individuum, Munich, 1991, pp. 43-63.

13 Kusche, M., Sofonisba Anguissola al servizio dei re di Spagna, Sofonisba e il ritratto di rappresentanza ufficiale nella corte spagnola, en Catálogo de la Exposición «Sofonisba Anguissola e le sue sorelle, Cremona, 1994, p. 89-151.

14 Kusche, 1964, p. 24.

15 Kusche, 1994 , p. 127 , fig. 28

16 Kusche, 1989, p. 400, nota 48

17 Kusche, 1964, p. 197.

18 Kusche, 1964, pp. 197-98. 

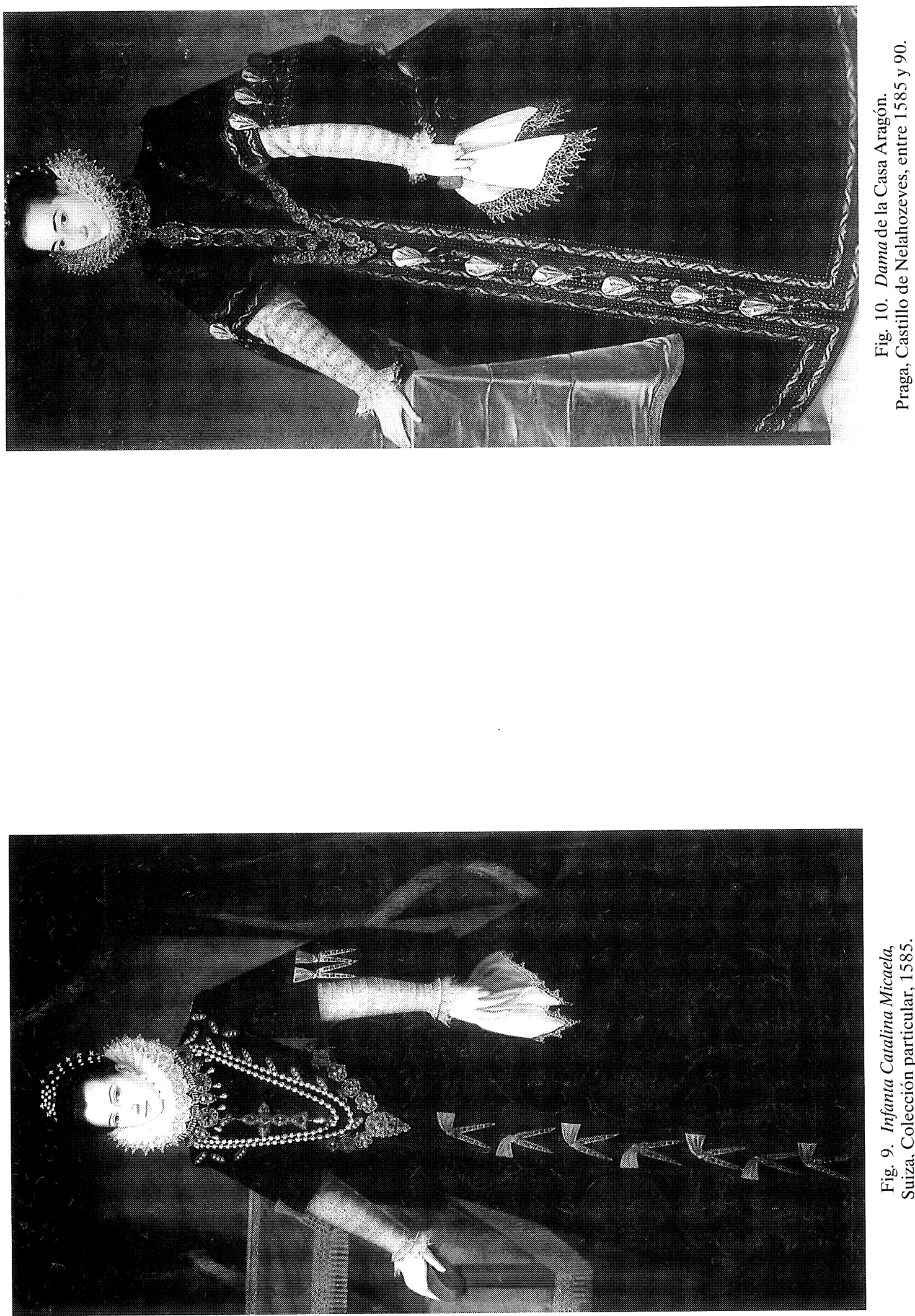

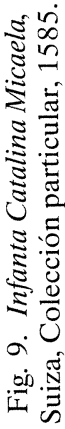



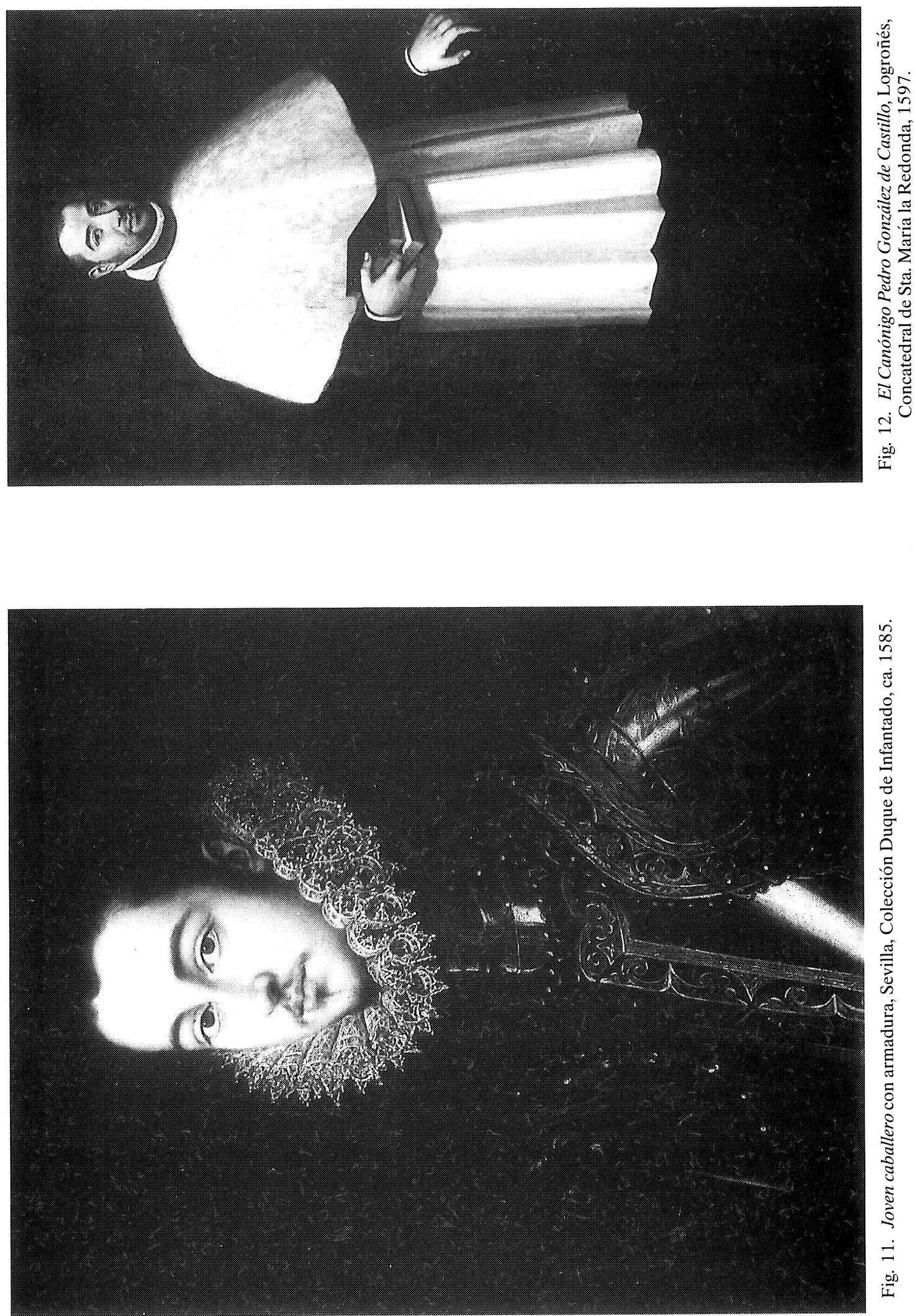
res. También en este retrato, por lo tanto, se repite la postura de cuerpo y manos de los dos retratos de dama que hemos recuperado aquí, de Isabel de Francia y Margarita de Cardona.

Pero el retrato de la Infanta, en contraste a los anteriores, es muy cortesano, mucho más distante en la expresión, menos realista, más idealizado. Esto hace que el retrato parezca más amable y al mismo tiempo más representativo que el que, en esta ocasión, pintó de ella Sánchez Coello (Monasterio de S. Lorenzo del Escorial) ${ }^{19}$ y también es mucho más oficial que el que de ella hizo, ya en Italia - justo después de la boda, es decir casi en la misma fecha- Sofonisba Anguissola (París, Embajada de España) ${ }^{20}$. El retrato de Pantoja parece que le gustó a la Infanta, porque debió de llevarse el original o una copia a Turín, dado que años después, en 1599, Sofonisba Anguissola sin duda lo vio allí, ya que en él se basa para su famoso retrato de Isabel Clara Eugenia (París, Embajada de España) ${ }^{21}$. Este coincide con el de Catalina en el volumen de la figura, en la relación de ésta con la estancia, en la postura de la figura, en la manera de colocar silla y cortinajes, y hasta en el detalle de los jazmines en el pelo.

Aproximadamente a los años 1585-90 pertenece un retrato de Una dama probablemente de la casa de Aragón (fig. 10), emparentada con los Pernstein, proveniente también de la propiedad Pernstein/Lobkowitz (hoy Castillo de Nelahozeve) que ya fue atribuido a Pantoja por Dvorak 22.

De postura también casi idéntica a la de Isabel de Francia y Margarita de Cardona, deja ver una tendencia creciente de representatividad que se refleja también en la mayor seriedad del rostro. El magnífico vestido está visto desde abajo, aumentando la altura e importancia de la dama, así como Pantoja lo haría en el futuro en sus retratos de reina. La dama se apoya con su derecha en una mesa cubierta de terciopelo rojo y sujeta en la izquierda, guantes y pañuelo. La saya negra con mangas redondas, asomando debajo las blancas del jubón, está profusamente guarnecida y bordada en oro y adornada con puntas. La lechuguilla ya tapa casi las orejas y deja ver debajo de ella un rico collar con colgante.

Un poco anterior debió ser pintado el busto de un caballero joven (Sevilla, Colección Duque de Infantado, fig. 11), muy elegante y muy detallista. Su rostro joven, con bigote y barba naciente, no sonríe, pero tiene en sus rasgos aún la blandura y belleza de adolescente, que le da también a este cuadro un encanto amable que los retratos posteriores no tienen.

En la técnica de los encajes, en las luces de la armadura, en su fina ornamentación, en la forma de concentrar la luz en la cara y reflejaría sobre la armadura se relaciona con los retratos de damas que hemos mencionado.

Desde 1590 Pantoja comienza a pintar para el futuro Felipe III. Existen, como ya expuse en mi biografia del pintor, varios retratos de Felipe, principe, el último de $1598{ }^{23}$. Hasta ahora no se conocían de estos años ningunos otros retratos masculinos que éstos, aparte del del Duque de Saldaña, hijo segundo del Duque de Lerma, también de $1598{ }^{24}$.

Sin embargo, existe en la Concatedral de Sta. María la Redonda en Logroño un retrato del DOCTOR PETRUS GONZALEZ DE CASTILLO, CANONICUS MAGISTRATIS ALMA ECCLESIA CONCHENSIS AETATIS SUA ANNO TRIGESIMO QUARTO (fig. 12). Esta firmado y fechado en 159725 .

19 Kusche, 1991 , p. 58 , fig. p. 58

20 Kusche, 1994, pp. 141, 254, 255, fig. 6, p. 30.

21 Kusche, M., Sofonisba Anguissola II. La vuelta a Italia, Paragone 513, 1992, pp. 25-26; Kusche, Sofonisba e il ritratto di rappresentanza ufficiale, op. cit., pp. 147, 258, fig. 259.

22 M. Dvorak, Spanische Bildnisse einer oesterreichischen Ahnengalerie, Kunstgeschichtliches Jahrbuch der K.K. Zentralkomission, Heft I, Viena, 1907.

23 Kusche, 1968, pp. 141-143, figs. 2, 3, 4, 6.

24 Kusche, 1968, p. 143, fig. 5.

25 Inventario artístico de Logroño y su provincia, vol. II, dirigido por José Gabriel Moya Valgañón, Madrid, 1976, p. 308. 
Fue González después de canónigo en Cuenca, obispo de Calahorra y -mecenas. También aquí, Pantoja sigue, en contraste con sus retratos del joven Principe y del Duque -serios, dignos, cortesanos- con la misma interpretación abierta y amable del personaje, como ya la hemos visto en sus retratos de dama, pero aquí el cuerpo - como en el de la dama de la Casa Aragón en Nelahozeve- ya se ha convertido en un soporte de la cara. La calidad de las telas es dura, los pliegues blancos parecen de papel, el tejido de la capa no se define, la postura estereotipada: en una mano lleva un misal o un breviario, la otra la apoya en una mesa.

El contraste entre el vivo realismo de la cara y el cuerpo inmóvil serán desde ahora las características de Pantoja.

Hay un sólo retrato, en estos años ya maduros, en el que Pantoja logra escapar de esta tendencia y -sorprendentemente- se trata de un retrato de carácter completamente oficial, un retrato de representación. Desde luego representa un personaje joven y apuesto, al principe heredero de Saboya. Felipe Manuel (fig. 13) -bautizado con los nombres de los dos abuelos: el de Felipe II y el del caudillo de S. Quintin, Manuel Filiberto- hijo de la Infanta Catalina Micaela, a la que, como vimos, Pantoja también retrató en su día, y para cuyas exequias, en 1597, recién nombrado pintor de cámara del Rey, tuvo que pintar todo lo necesario para la ceremonia.

Este nieto de Felipe II, al que, como los demás, tanto ansiaba conocer su abuelo materno ${ }^{26}$ llegó por fin a España en 1603, con diecisiete años, junto a su hermano Victor Amadeo de dieciséis, para terminar ambos su educación en España -ya años después de la muerte de su madre en 1597 y de Felipe II en 1598. Murió Felipe Manuel inesperadamente, en Valladolid en 1605, truncándose todas las esperanzas puestas en él; tuvo que ser pintado el retrato pues entre 1603 y 1605.

El Museo del Prado posee dos de Felipe Manuel: uno, en el que tiene un año, que se encuentra en la Embajada Española de Buenos Aires y otro, en el Museo de Sta. Cruz en Toledo, de cinco años ${ }^{27}$. En éste ya se aprecian claramente los rasgos del adulto. Una inscripción antigua en el presente retrato confirma además la identidad del personaje.

Sobre la identidad del autor no hay duda comparando el retrato con otros de él de esta época, ante todo con el de Felipe III (fig. 14) en el Castillo de Ambras (Innsbruck) de ca. 1598 28, con el que conviene en el afán marcado de representación, en su riqueza y atributos. En ambos retratos la figura del respectivo heredero, de España y de Savoya (primo del rey y de sangre real como él), está situada delante de un pomposo cortinaje que llena el fondo y se pliega por el lado izquierdo. En ambos llama la atención la lujosísima armadura, adornada en el caso de Felipe por el Toisón, en el de Felipe Manuel por la medalla de la orden de La Anunciada. También el dibujo de las calzas es casi idéntico. Ambos jóvenes llevan la espada y además el bastón de mando, los guantes están distribuidos de manera casi igual encima de los respectivos bufetes.

Sin embargo, el retrato de Felipe III es, como todos los que Pantoja pintó de él, poco agraciado, y además poco logrado el tamaño de cuerpo entero, en contraste, el retrato de Felipe Manuel es un soberbio retrato de representación, pintado con grandeza y soltura, sin duda el retrato de representación más logrado de Pantoja. Vemos claramente que el pintor se deja influenciar del aspecto del modelo. Acostumbrado al modelo real nada inspirante de Felipe III, aquí, ante este joven, por fin es capaz de encontrar un fórmula justa para un retrato oficial masculino. Aunque no puede trasmitir la simpatía del sujeto a través de una sonrisa como en retratos no oficiales, salva la arrogancia del joven príncipe prestando atención a toda su figura, o mejor dicho a lo que de ella se ve. Suprime las piernas que siempre se la dan mal, le da volumen a la parte superior del cuerpo, frenando el gusto de sus últimos años por la disolución de la figura en una espe-

\footnotetext{
26 Bouza Alvarez, F. J., Cartas de Felipe II a sus hijas, op. cit., p. 152.

27 El Niño en el Museo del Prado, Catálogo de Exposición, Madrid, 1983/84, n. 45.

28 Kusche, 1968, p. 144, fig. 6.
} 

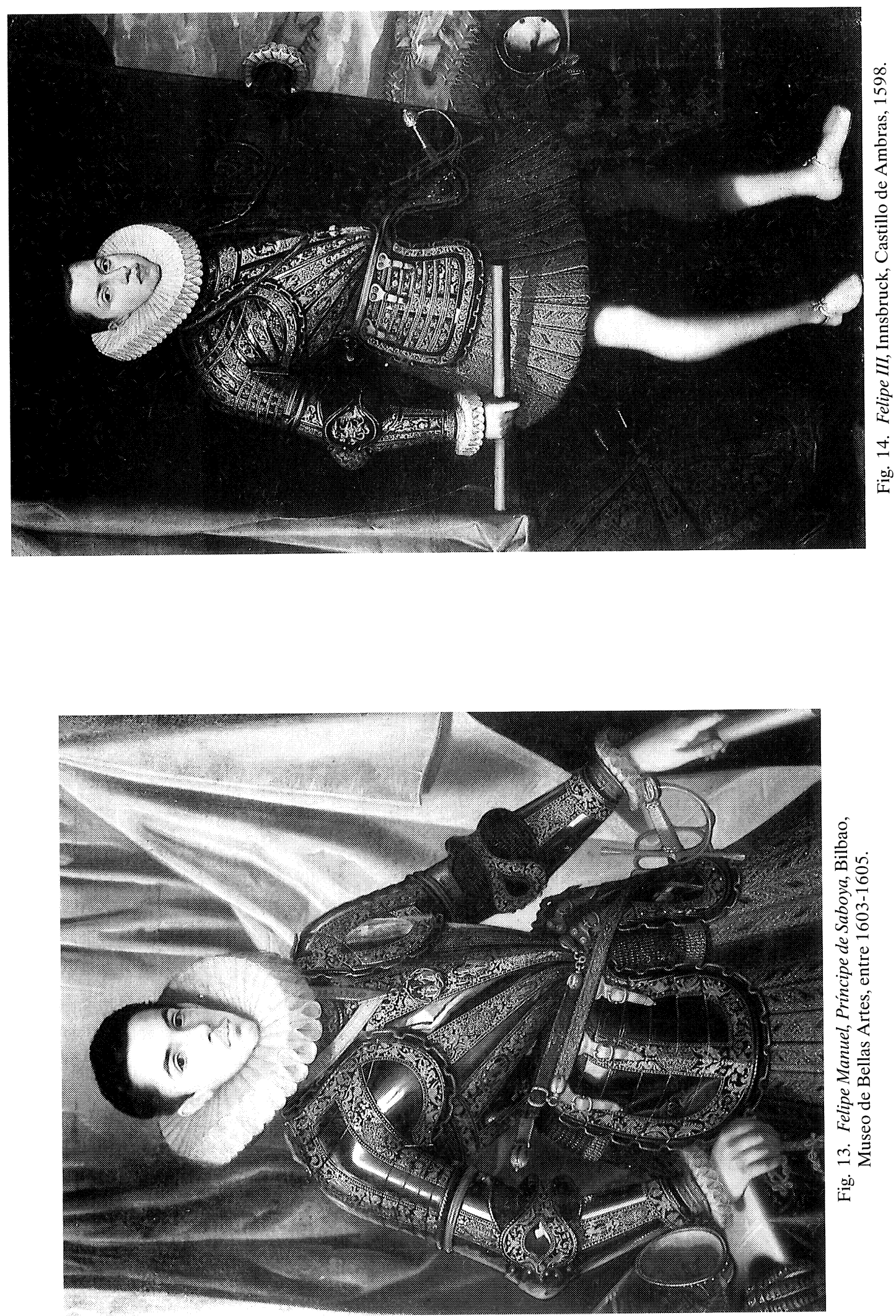
cie de icono ornamental y exalta al personaje con una gama hermosísima de tonos: negro, oro y blanco, envuelto todo en una llamarada de rojo que se refleja en cara, armadura, y manos.

Un retrato de la Infanta Ana Mauricia que se encuentra en The Baltimore Museum of Art (fig. 15) también retrato de representación oficial, representa igualmente con mucha sensibilidad al pequeño personaje de cinco años, aunque no tiene la espontaneidad de los niños no reales. Repite la interpretación de la Infanta del doble retrato con el Infante Felipe (IV) de 1607, en el Kunsthistorisches Museum en Viena, de 1607 (fig. 16) ${ }^{29}$. pero el retrato individual la acerca más al espectador. La extrema sobrecarga de bordados del traje y de joyas, más exagerada aún que en el retrato con el hermano, así como la posición de la mano derecha que juega con las perlas como una dama -mientras que en el retrato doble sujetaba con ella la del hermano- hace aparecer a la Infanta - por contraste- aún más infantil y tierna que en el retrato de los dos infantes juntos. Probablemente este retrato, sin duda recortado, como se ve en la mano izquierda, habrá sido de cuerpo entero, subrayando con el tamaño pequeño de toda la figura aún más la corta edad de la niña, como lo hace un retrato suyo de 1604, con tres años, de cuerpo entero, en Viena, Kunsthistorisches Museum ${ }^{30}$.

La simpatía humana tan marcada en sus retratos jóvenes también impregna a un retrato de dama con niño (Madrid, Colección Particular, figs. 17 y 18 según el tamaño de la lechuguilla y el tipo del encaje, ya del primer decenio del siglo XVII. Es más representativo aún que los retratos anteriores de dama que hemos visto. Debió ser dama principal porque el pintor la sitúa en una gran terraza con balustrada, que deja ver el paisaje montañoso y la encuadra con un enorme cortinaje, al estilo del de la Reina Doña Margarita en el Museo del Prado, y sin duda influenciado, en balustrada y paisaje, por el primer retrato que hizo Sofonisba, Anguissola de Isabel de Valois (Toledo, Colección Particular) ${ }^{31}$.

Pero Pantoja no le da a este retrato el empaque serio que se ve en sus retratos femeninos reales, vuelve en la expresión de madre e hijo a la alegre naturalidad de sus primeros retratos. El niño, con su sonrisa espontánea, sentado en un cojín sobre el poyete de la terraza, y destacando con su vestimenta blanca del negro del traje de la madre, parece apretar con fuerza contra su pecho una jaula con un pájaro, haciendo ver que le pertenece y la madre presenta a su hijo con una sonrisa entre divertida y orgullosa de él.

Al final quiero mostrar dos miniaturas de Pantoja (Sevilla, Coleccion Infantado) que nos pueden dar una idea del carácter de esta importante faceta de su producción.

Ambas están pintadas en cobre. Una de ojos oscuros (fig. 19, $54 \mathrm{~mm} \times 43 \mathrm{~mm}$ ) debe fecharse al final de los 1580 como se ve por la lechugilla que casi tapa la oreja y la trenza que corona la cabeza.

La otra de ojos más claros (fig. 20,62 $\times 49 \mathrm{~mm}$ ) es posterior, de los últimos años del siglo, como lo demuestra la lechuguilla exagerada y el peinado en copete. Las dos tienen una técnica muy segura y detallista, una expresión muy alegre y abierta. Ambas recuerdan el busto de dama en el Museo del Prado ${ }^{32}$. Pero aqui en las miniaturas Pantoja, ayudado por el minúsculo tamaño, desarrolla una técnica deliciosamente suelta y espumosa. Una vez liberado de los cuerpos que a él le exigian un trato tán hierático y oficial, aqui puede y debe concentrarse completamente en los rostros y lo hace con una psicologia tan fina como sorprendente, mucho mayor y sútil que la de sus retratos grandes, oficiales. Tiene el placer de envolver estas cabecitas en un primer marco, en una nube de encaje, sin tener que definirse más, lo que le deja al expectador la posibilidad de agrandar la imagen de la dama con igual vaporosidad.

\footnotetext{
29 Kusche, 1964, p. 156, fig. 23.

30 Kusche, 1964, p. 159, fig. 29.

31 Kusche, 1994, p. 127, fig. 17.

32 Kusche, 1964, p. 165, fig. 34.
} 

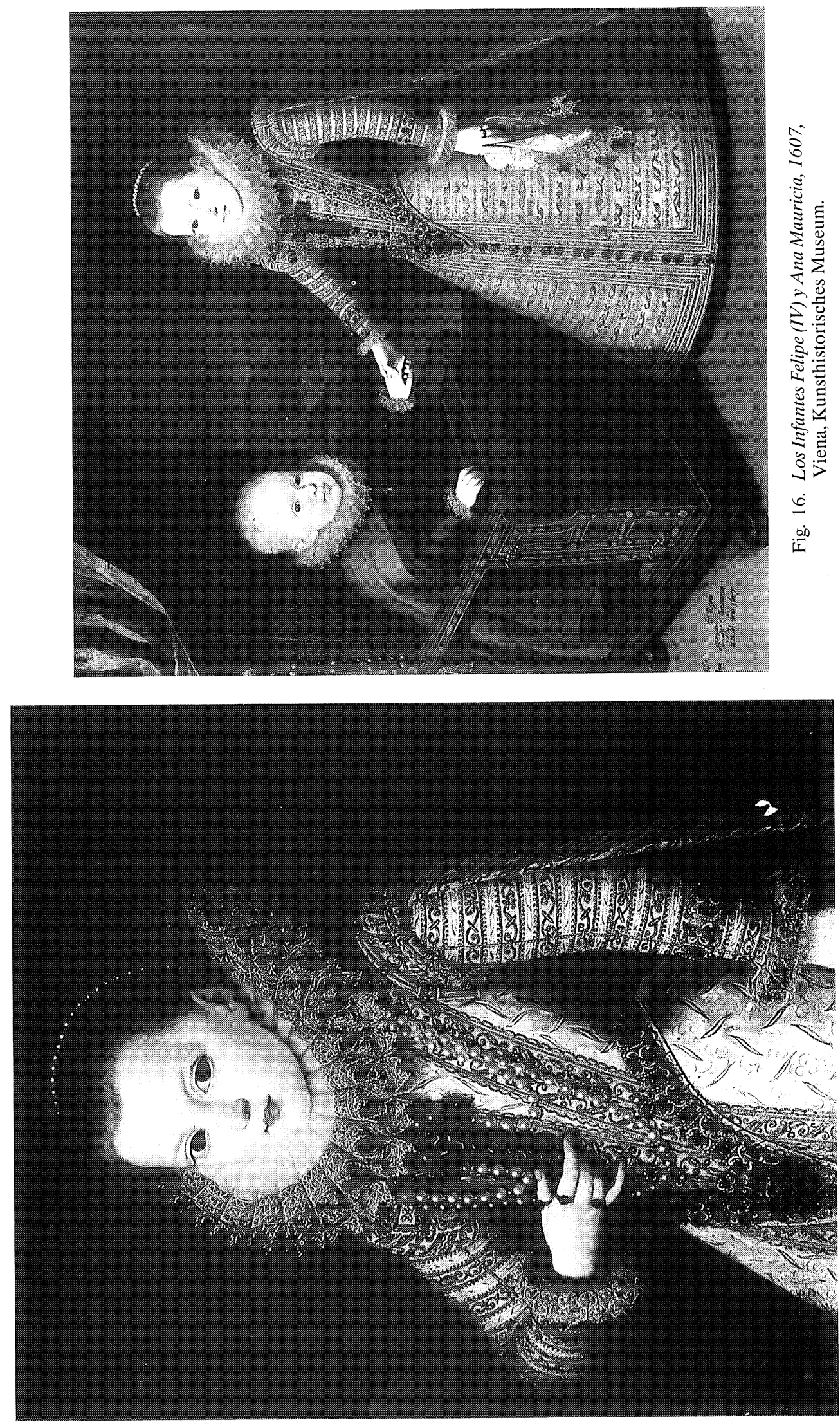

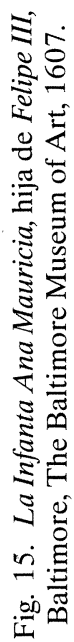




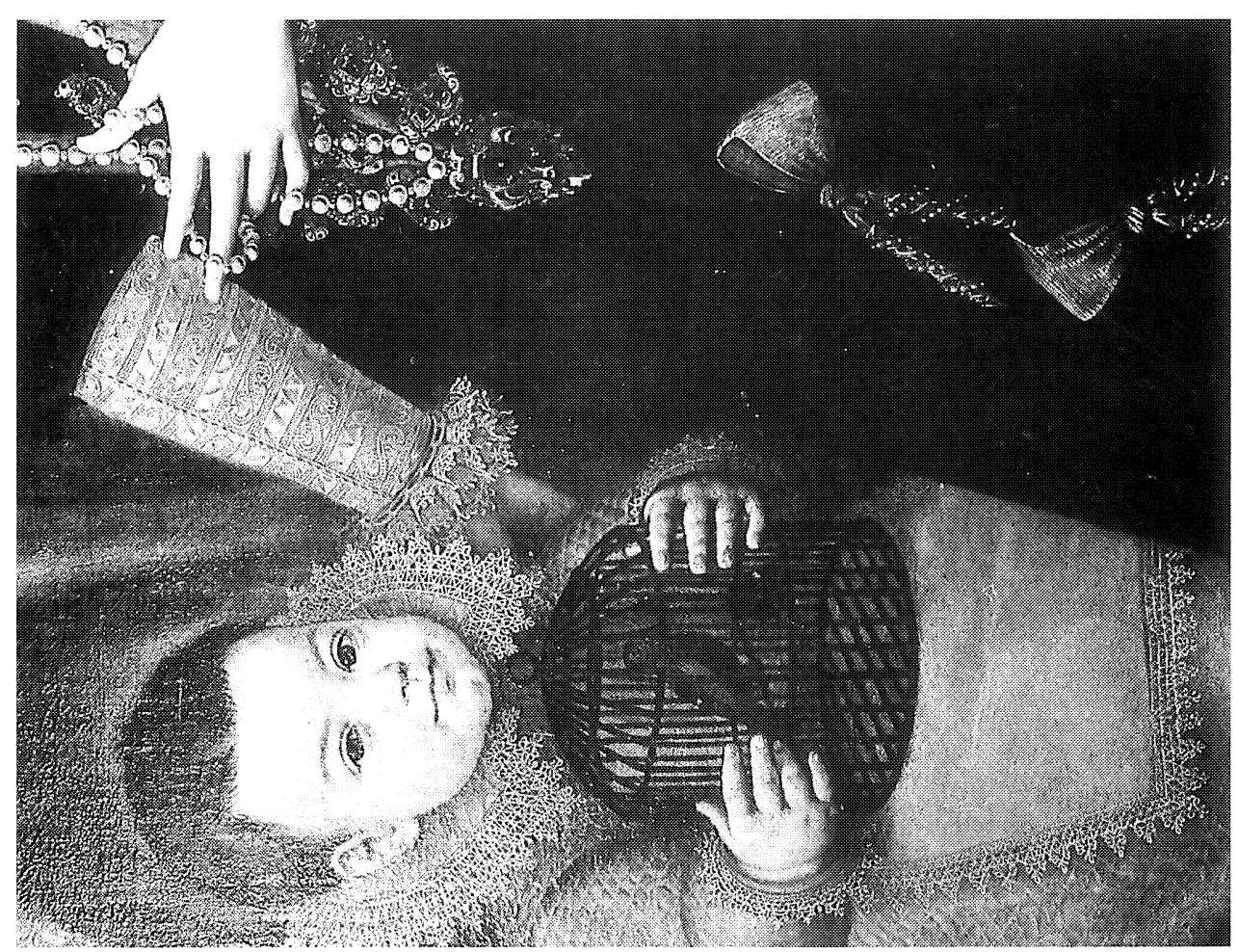

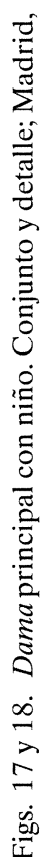
$\stackrel{\infty}{\sim}$

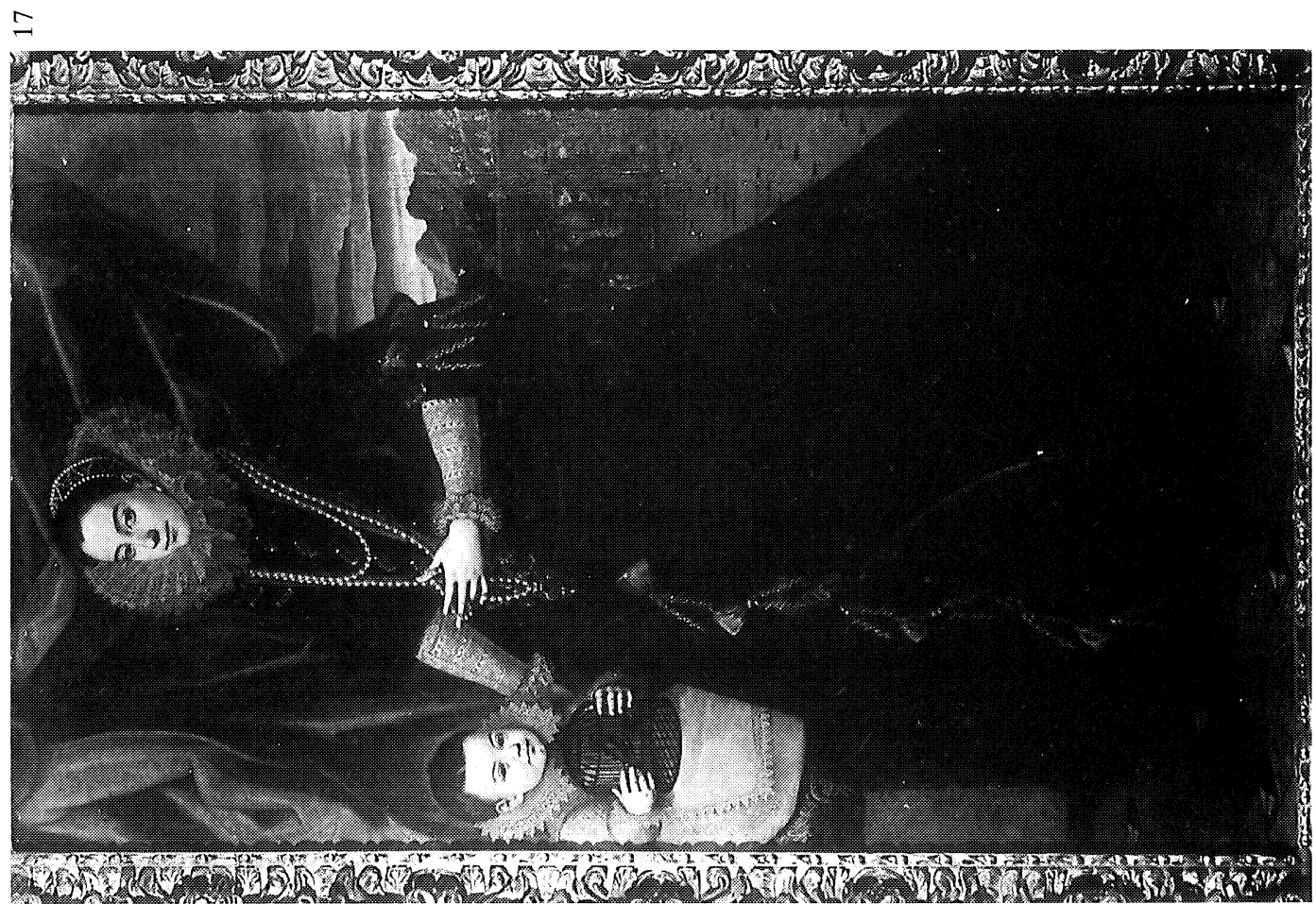




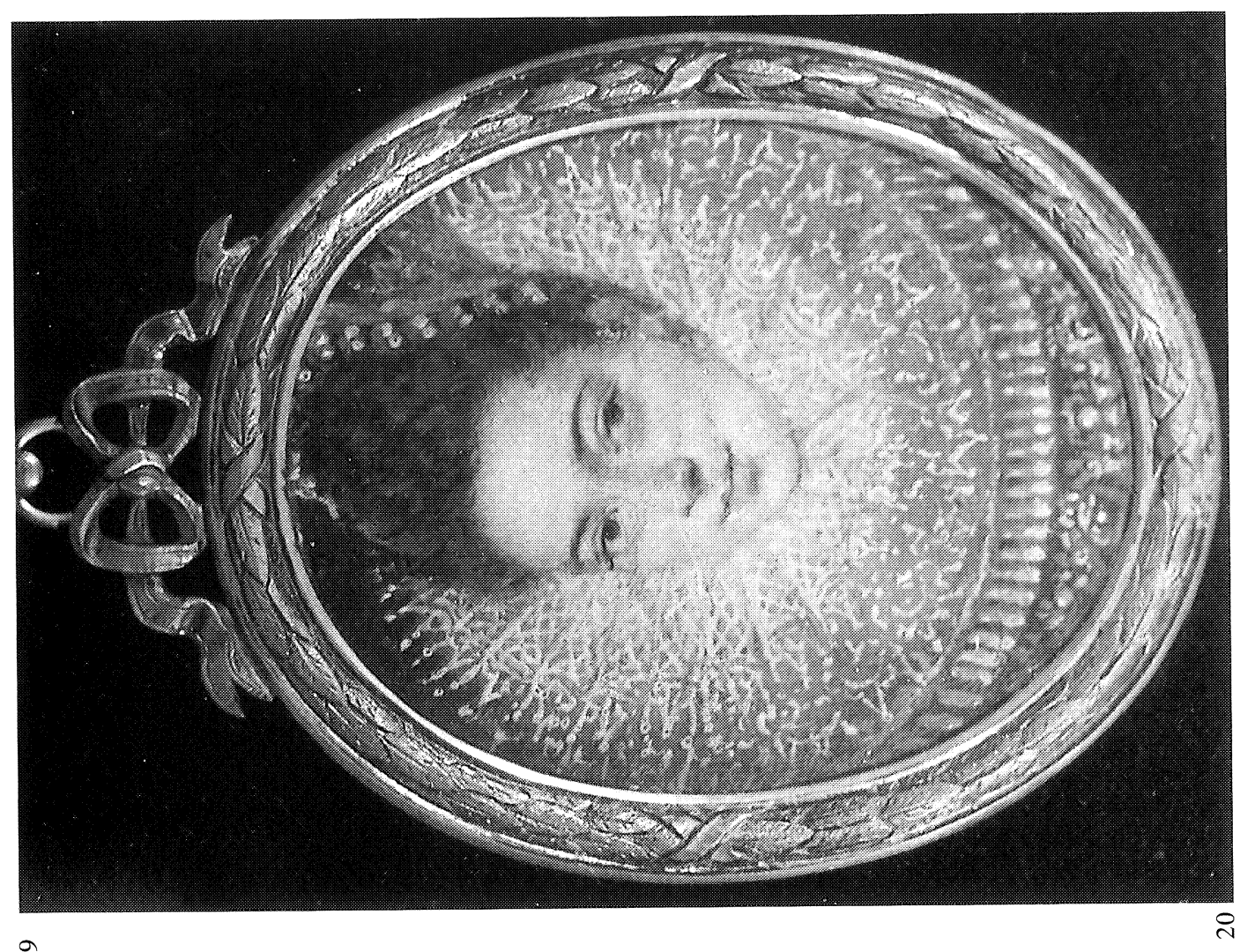

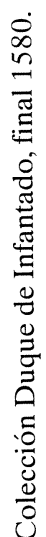

2

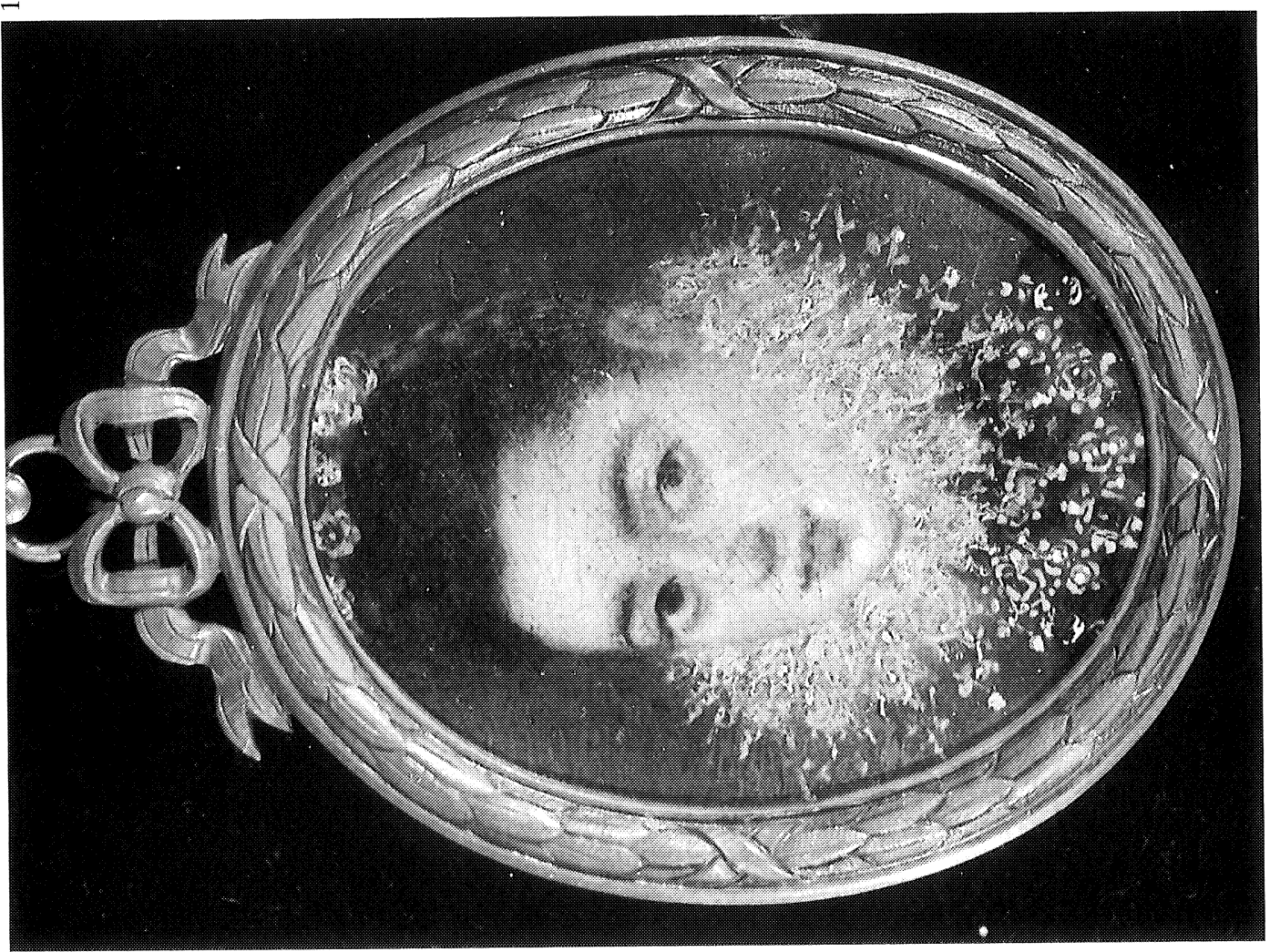

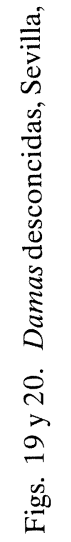


Comparándo esta obra "nueva» de Pantoja con la mayoría de sus retratos oficiales de corte, con la obra de sus años maduros, se observa lo contrario de lo que ocurre en los grandes maestros. Con los años su pintura no se haría más fluida, más ligera, más independiente, sino quedaría apresada cada vez más en las normas cortesanas.

La naturalidad amable de las caras de sus cuadros jóvenes llena estas obras de una vida sorprendente. Deja olvidar que también en ellos prevalece la rigidez de los cuerpos, como en sus cuadros maduros, que carecen de volumen y sus trajes de sensualidad textil, faltas que se disimulan con la pincelada fina, con la riqueza ornamental de los trajes y ante todo con un refinado y suave colorido.

Pero son estos retratos de su primera época los que nos muestran las grandes cualidades de Pantoja como retratista, una vitalidad que después se va marchitando, una delicadeza psicológica, a veces cierto sentido del humor, que sólo sobrevive en retratos de particulares y en los retratos infantiles o de personas jóvenes, mientras que los oficiales de la familia real, de grandes personajes, cada vez más parecen tener caras en realce, como de porcelana, de gran plasticidad pero inmóviles, enmarcadas por las enormes gorgueras, y con el cuerpo plano, reducido ya sólo a un soporte. Excepción de esta regla son los retratos del Principe de Saboya y de la Infanta Ana Mauricia, sin duda por ser jóvenes y agraciados.

Los retratos recuperados para Pantoja, nos hacen comprender que su arte -su colorido exquisito, la extraña mezcla entre realismo y ceremoniosidad de sus personajes, que puede resultar caricaturesca - tuvo gran repercusión en los grandes retratistas de las generaciones siguientes. Ambas cualidades seguirían perteneciendo a las caracteristicas más típicas del retrato español.

Espero que estas nuevas identificaciones ayuden a recuperar más obras de Pantoja -al que hemos conocido aquí como a un pintor de nuevas y mayores cualidades de las que se conocían en él. Muy especialmente pudieran aún aparecer miniaturas -las debió de pintar por docenas, como se ve por su inventario y sus testamentos- y a juzgar por los ejemplos presentados, esta obra pequeña, fue grande en belleza, y pertenece a lo más atractivo de la obra del pintor. 